\title{
The DEA Appraisal Model Analysis of the Liberal Arts Scientific Research Efficiency in Sciences and Engineering University
}

\author{
Hanfeng Liu, Linbo Si \\ Yanshan University, Qinhuangdao 066004, China \\ liuhf@ysu.edu.cn,gjzx@ysu.edu.cn
}

\begin{abstract}
This paper adopted the Data Envelopment Analysis method to build the DEA evaluation model of the efficiency of inputs and outputs of the liberal arts scientific research, the conclusion as following: the liberal arts scientific research efficiency is relatively lower in sciences and engineering university, and most of them is in the stage, which presents the trend: with the increased scale, efficiency gains. Thus, the increasing of liberal arts scientific research's investment scale and the formation of a high level research team are the effective way,which many sciences and engineering university to improve the efficiency of scientific research.
\end{abstract}

Index Terms - Sciences and Engineering University, Liberal Arts Research Efficiency, DEA Evaluation Model

\section{Introduction}

Recent years, with the continuous development of the liberal arts in science and engineering university, the outputs of social sciences research achievements are increasing, and some key universities of science and engineering have occupied an important position in the areas of Humanities and Social Science Research. However, in science and engineering universities, from the view of research achievements, it still has a large distance between the humanities and social science subjects and the science and engineering subjects. It is not reasonable to compare the efficiency of these two disciplines directly. There are two reasons, firstly there are more differences between these two disciplines in the terms of research activities; secondly, in the terms of financial input and policy support, the supports which the science and engineering subject get are more than the social science subject. In this paper, we will use the Data Envelopment Analysis method to judge the validity of the input scale, from the view of the quantitative relationship of the inputs and outputs of humanities and social science subjects. Finally, draw valid conclusions and propose improvement measures.

\section{Introducing the Basic Model of Dea-The Model of C2R}

The data envelopment analysis (DEA), which was based on efficiency concept, is a new efficiency evaluation method developed by W.W. Copper, A.Charnes and other famous American operation researchers in 1978.In order to reflect whether DMU could meet with "the investment in as little as possible to gain the maximum benefits "or not, it will analysis the effectiveness of DMU (Decision Making Units) through the basic of the sample data divided into input index and output index[1].

The basic idea is to gain the quantitative index of the overall efficiency of every DMU, through the comprehensive analysis of input and output data, which could determine whether DMU is DEA efficiency or not. Then, based on the basic principles of DEA, the model of $C^{2} R$ to evaluate the scientific research efficiency of liberal arts units in science and engineering universities could be established.

Assuming that there are $\mathrm{n}$ sciences and engineering universities(Decision Making Units DMU), each of the sciences and engineering universities has $m$ kind of inputs (the consumption of resources) and s kind of outputs (effective information), their corresponding weight coefficients are $V=\left(v_{1}, v_{2}, \cdots, v_{m}\right)^{T} \quad, \quad U=\left(u 1, u 2, \cdots, u_{s}\right)^{T} \quad$ respectively. $X_{j}=\left(x_{1 j}, x_{2 j}, \cdots, x_{m j}\right)^{T}, Y_{j}=\left(y_{1 j}, y_{2}, \cdots, y_{s j}\right)^{T}$ are the inputs and outputs of the $j$ sciences and engineering university, respectively. Among them, $X_{i j}$ is the total input that the $j$ sciences and engineering university input to the $i$ type, $y_{i j}$ is the total output that the $\mathrm{j}$ sciences and engineering university input to the $r$ type, $v_{i}$ is a measurement of the $i$ input, $U_{r}$ is a measurement of the $r$ output. Every sciences and engineering university has the corresponding efficiency evaluation index:

$h_{j}=\frac{\sum_{r=1}^{s} u_{r} y_{r j}}{\sum_{i=1}^{n} v_{i} x_{i j}}$ , we should select properly $v$ and $u$ which meet $h_{j} \leq 1$. Now doing the evaluation on the liberal arts scientific research efficiency of the No. $j_{0}$ sciences and engineering university, we regard the liberal arts scientific research efficiency index of the No. $j_{0}$ science and engineering university as the target, all of the being evaluated science and engineering universities' liberal arts scientific research efficiency index as the constraint, from $\mathrm{DMU}_{\mathrm{j} 0}$ to $\mathrm{DMU}_{0}$ for short, we get the most basic model is: 


$$
(P)\left\{\begin{array}{l}
\max =\frac{U^{T} Y_{\mathrm{O}}}{V^{T} X_{\mathrm{o}}} \\
\frac{U^{T} Y_{\mathrm{O}}}{V^{T} X_{\mathrm{o}}}=h_{j}, j=1,2, \cdots n \\
v \geq \mathrm{O}, u \geq 0
\end{array}\right\}
$$

The upper formula that is fractional programming on the basic of ratio definition goes against calculation. The formula can be converted to an equivalent linear programming problem by Charnes-Cooper transformation. In order to calculate conveniently, we introduced nonarchimedean infinitesimal. Its dual programming problem is [2]:

$$
(D \varepsilon)\left\{\begin{array}{l}
\min \left[\theta-\varepsilon\left(\left[e^{-}\right]^{T} S^{-}+\left[e^{-}\right]^{T} S^{+}\right)\right] \\
s . t \cdot \sum_{j=1}^{n} X_{j} \lambda_{j}+S^{-}=\theta X_{\mathrm{O}} \\
\sum_{J=1}^{N} Y_{j} \lambda_{j}-S^{+}=Y_{\mathrm{O}} \\
\lambda_{j} \geq 0, j=1,2, \cdots n ; S^{+} \geq 0, S^{+} \mathrm{O}, S \geq 0
\end{array}\right\}
$$

Among them $\left[e^{-}\right]^{T}=\left[1,1, \cdots 1 \in E_{m},\left[e^{+}\right]^{T}\right] \in E_{s}$, If the optimal solutions of the programming problem $(D \varepsilon)$ were $\lambda^{0}, s^{0-}, s^{0+}, \theta^{0}$, we could get the conclusion as following[3]:

$$
\text { If } \theta^{0}=1 \text {, decision making units } D M U_{j 0} \text { is weak DEA }
$$

efficiency, that is to say, decision making units $D M U_{j 0}$ is technological efficiency but not scale efficiency at the same time , and vice versa.

If $\theta^{0}=1$, and $s^{0-}=0, s^{0+}=0$, decision making units $D M U_{j 0}$ is DEA efficiency, that is to say, decision making units $D M U_{j 0}$ is valid not only in technique but also in scale. If $\theta^{0} \prec 1$, decision making units $D M U_{j 0}$ isn't DEA efficiency.

$$
\text { If } \sum_{j=1}^{n} \lambda_{j}^{0} / \theta^{0}=1
$$
, decision making units $D M U_{j 0}$ has appropriate investment scale, that is to say, decision making units $D M U_{j 0}$ is constant returns to scale (optimal scale).

$$
\text { If } \sum_{j=1}^{n} \lambda_{j}^{0} / \theta^{0} \prec 1
$$
shows increasing inputs can make output level ascend with an increasing rate.

$$
\text { If } \sum_{j=1}^{n} \lambda_{j}^{0} / \theta^{0} \succ 1 \text {, returns-to-scale is diminishing. }
$$

\section{The DEA Empirical Analysis of the Liberal Arts Units' Scientific Research Efficiency in Sciences and Engineering University}

The Definition and Selection of DMU: DMU is the decision making units used for the evaluation and comparison of DEA .When Selecting DMU, we must take the same market conditions, and the DMU with the same configuration as the selection standard less the evaluation result should be meaningless because of different foothold condition of the units receiving evaluation. The DMU with the same configuration should have the following characteristics: All decision making units must perform the same tasks and have similar goals.

All decision making units must operate under the same market conditions. The input and output to display the performance characteristics of all decision making units must be the same, but the intensity or amplitude of the input and output may be different. Generally speaking, the greater the number of DMU, the more defined the relationship between input and output. Therefore, the selection of DMU number can be decided by some scholars obtaining rule of thumb the empirical experience, that is to say, the number of units receiving evaluation is at least two times than the sum of input and output projects[4].

The Choice of Input and Output Index: The scientific research activities in universities is a complex activity with multi input (people, funds, material, etc.) and multi output (papers, achievements, achievements transformation, etc.) So it is a complex system project in evaluating the input-output efficiency of scientific research activities in universities[5]. The sciences and engineering research achievement is embodied in not only the number of the published scientific and technical monographs, the completed scientific research projects and the published academic papers, but also the amount of scientific achievements transformation. The other hand, the form of the liberal arts scientific research achievements is mainly the number of published monographs, undertaken scientific projects, published papers and won prizes. Few of the liberal arts scientific research achievements can be transformed into amount directly.

For example, Yanshan University regards the number of papers published in EI, CSSCI, CSCD, SCD and other including periodicals as the important reference of the liberal arts scientific research achievements. Therefore, the paper regards the two indexes of scientific research human resources and funds as the input index of the liberal arts scientific research efficiency evaluation and regards the three indexes of the published monograph words, the number of the completed scientific research projects and the number of academic papers as the output index of the liberal arts scientific research efficiency evaluation.( as shown in the TABLE I). 
TABLE I The index system explanation of the Liberal Arts Research Efficiency Evaluation in Sciences and Engineering University

\begin{tabular}{|c|c|c|}
\hline \multirow[t]{2}{*}{ Input Index X } & Human resources in scientific research & $\begin{array}{l}\text { the qualification of teachers in } X_{1}, X_{1}=3 z_{1}+2 z_{2}+z_{3}, z_{1}, z_{2}, z_{3} \text { express professor, vice } \\
\text { professor, etc, respectively, the contribution size expressed by the variable coefficient }\end{array}$ \\
\hline & Scientific research funds & Scientific research fund/ten thousand yuan in $X_{2}$ \\
\hline \multirow{3}{*}{ Output Index Y } & Publishing monograph & Publishing monograph/ten thousand words in $\mathrm{Y}_{1}$ \\
\hline & $\begin{array}{l}\text { The number of scientific research projects } \\
\text { completed }\end{array}$ & $\begin{array}{l}\text { The completed scientific research projects } / \text { term in } \mathrm{Y}_{2}, \mathrm{Y}_{1}=3 \mathrm{Z}_{5}+2_{6}+\mathrm{Z}_{7}, \mathrm{Z}_{5}, \mathrm{Z}_{6}, \mathrm{Z}_{7} \text { express state } \\
\text { project, provincial project and city level project, respectively, the contribution size } \\
\text { expressed by the variable coefficient }\end{array}$ \\
\hline & The number of published academic papers & $\begin{array}{l}\text { The number of the academic papers published in the core journals at home and abroad } \\
\text { expressed by } \mathrm{Y}_{3}\end{array}$ \\
\hline
\end{tabular}

Empirical Analysis: In order to understand the liberal arts scientific research efficiency in sciences and engineering university comprehensively and deeply, and also meet the modeling conditions mentioned above, we selected 10 liberal arts units in Chinese science and engineering universities in 2011 as the samples which include Beijing Jiaotong University, Wuhan University of Technology, Beihang University, South China University of Technology, Kunming University of Science and Technology, Yanshan University, Guangdong University of Technology, Chengdu University of Technology, Liaoning Technical University and Hubei University of Technology. Due to the index data that comes from the internet, it may not be the most detailed result. Therefore, the result only has reference value rather than ranking of specific scientific research efficiency for each unit.

With the empirical analysis of data and research methods in 2011, it can get the result of TABLE II; all the results are got from the operations of efficiency analysis software that is named EMS.

TABLE II The score and ranking of the liberal arts units scientific research efficiency in Sciences and Engineering universities in 2011

\begin{tabular}{|l|c|c|}
\hline \multicolumn{1}{|c|}{ DMU } & Score & Ranking \\
\hline U1 Beijing Jiaotong University & 1.1037 & 1 \\
\hline U2 Wuhan University of Technology & 1.0969 & 2 \\
\hline U3 Beihang University & 1.0637 & 3 \\
\hline U4 South China University of Technology & 0.9837 & 4 \\
\hline $\begin{array}{l}\text { U5 Kunming University of Science and } \\
\text { Technology }\end{array}$ & 0.9659 & 5 \\
\hline U6 Yanshan University & 0.9457 & 6 \\
\hline U7 Guangdong University of Technology & 0.9275 & 7 \\
\hline U8 Chengdu University of Technology & 0.9142 & 8 \\
\hline U9 Liaoning Technical University & 0.8849 & 9 \\
\hline U10 Hubei University of Technology & 0.8635 & 10 \\
\hline
\end{tabular}

\section{CONCLUSION}

The Calculation Results`Analysis of DEA Model: Based on the calculation results, we can know that only the liberal arts` scientific research efficiency value $\theta^{0}$ of three science and engineering universities, Beijing University of Technology, Wuhan University of Technology and Beijing University of Aeronautics Exceeds 1. Most of the liberal arts` scientific research efficiency value $\theta^{0}$ is almost below 1 . This shows that most of the liberal arts' scientific research efficiency value of the science and engineering universities is not very high. We can get the following reasons by the date of operation process:

The Deficiency of Human Resources in Scientific: The main reason of the low research efficiency is that the qualification of teachers in the liberal arts units of the science and technology universities is deficiency. For the example of South China University of Technology and Yanshan University, the faculty member $\mathrm{Z}$ of the politics and public management college in South China University of Technology is 80 . There are 9 professors $Z_{1}$ and 21 vice professors $Z_{2}$ among the faculty. There are 41 professors $Z_{1}$ and 46 vice professors $\mathrm{Z}_{2}$ among the 226 faculties in mechanical engineering of the university. There are 32 professors $Z_{1}, 52$ vice professors $Z_{2}$ and 41 lecturers $Z_{3}$ among 136 faculties in literature and legal college of Yanshan University. There are 75 professors $Z_{1}$ and 52 vice professors $Z_{2}$ among more than 300 faculties in mechanical engineering of the university. We can see that the faculty in Mechanical Engineering College of the sciences and engineering units of the two universities is so large, while the liberal arts units` is otherwise. It must lead to the short of researching time because of the deficiency of human resources in scientific and undertaking relative teaching task of teachers. As a result, scientific research achievements are few and efficiency is not high.

The Deficiency of Fund in Scientific: Every sciences and engineering university takes the sciences and engineering majors especially the distinctive ones as the focal point of the university development. Such university also makes some tendency on the science majors in researching fund and policy. The liberal arts majors have not been brought into the cortege of point development, so the relative investment is far from the one of sciences and engineering majors, which leads to the tension even deficiency of researching fund. As a result, the efficiency of scientific research is low. Take Yanshan University for example, the funding in the mechanical engineering of the university is tens times to the one of literature and legal college. The purpose of the article, which doesn't compare the scientific research fund between the science and engineering units and the liberal arts units, is to explain that the universities have different inclination on different majors in investment of scientific research. So we can 
get the relative reasonable conclusion by the transverse comparison of similar universities instead of the dim comparison between liberal arts majors and sciences and engineering majors when we evaluate the research efficiency.

The Approach of Improving the Liberal Arts Scientific Research Efficiency in Science and Engineering University: In the calculation results, such as Yanshan university, South China university of technology and some other universities, the ratio of liberal arts scientific research $\lambda^{0}$ and $\theta^{0}$ is less than 1 , which illustrates the efficiency of liberal arts scientific research in these universities is increasing return to the scale, namely increasing inputs can make the output level increase with increasing speed. This helps provide theoretical basis for the approach of improving the liberal arts scientific research efficiency in science and engineering university.

Optimizing teachers' team, and forming a high-level scientific research team. Science and engineering university scientific research administration department should implement talent introduce strategy, according to academic research direction and areas, establish high quality research team. At present, the university teachers bear the heavier teaching tasks generally, which is not good for establishing the scientific research team. According to the actual situations and needs of different units, universities can try to set up corresponding fulltime research positions, arrange fulltime scientific researchers through external recruitment or internal rotating station. Setting fulltime scientific researchers can concentrate superior resources specializing in tackling key problem of scientific research projects, so as to improve the efficiency of scientific research.
Increasing scientific research investment, and improving scientific research conditions. The input for scientific research includes funds and policies. Science and engineering universities should intensify the liberal arts scientific research investment, not only in the capital, but also in policy to encourage and support. Many science and engineering universities set technology department, which is mainly responsible for guidance and management of scientific research work, but the scientific research policy for science and engineering is not suitable for liberal arts scientific research. Science and engineering university scientific research administration department should understand correctly the differences of contents, methods, achievements of science and engineering and the liberal arts scientific research, follow the characteristics and development regularity of liberal arts scientific research, implement the policy actively, overall coordinate relationships. These universities with large liberal arts scale should establish special liberal arts scientific research management institution, which manages the liberal arts scientific research work separately.

\section{References}

[1] Q.L. Wei: The DEA Method of Evaluating Relative Efficiency-A New Field in Operations Research, (Renmin University of China Press, chain 1998), p.14 (In Chinese).

[2] W.J. Duan: Liaoning Education Research, (2007) No.6, p.48 (In Chinese).

[3] S.M. Sun, H.L. Xiang: Science and Science Technology Management, (2007) No.7, p.19 (In Chinese).

[4] Y.X. Wang, H.Y. Wang: Theory and Practice on Finance and Economics, (2007) No.3, p.114 (In Chinese).

[5] G.S.Lu, L. Liu: Academic Journal of Xi'an Jiaotong University (Social Science Edition), (2005) No.2, p.75-79 (In Chinese). 